\title{
Textural Evolution and Phase Transformation in Titania Membranes: Part 2.t-Supported Membranes
}

\author{
Krishnankutty-Nair P. Kumar, ${ }^{a}$ Klaas Keizer, ${ }^{a}$ Anthonie J. Burggraaf, ${ }^{a}$ Tatsuya Okubo, ${ }^{b}$ and \\ Hidetoshi Nagamoto ${ }^{b}$ \\ a Laboratory for Inorganic Chemistry, Materials Science and Catalysis, Faculty of Chemical \\ Technology, University of Twente, 7500 AE Enschede, The Netherlands \\ ${ }^{b}$ Engineering Research Institute, The University of Tokyo, 2-11-16 Yayoi, Bunkyo-ku, Tokyo 113, \\ Japan
}

\begin{abstract}
Nanostructural evolution and phase transformation in supported and unsupported titania membranes have been studied using Raman spectroscopy, X-ray diffraction (XRD) and field-emission scanning electron microscopy (FE-SEM). Densification of unsupported membranes started at ca. $450{ }^{\circ} \mathrm{C}$ and reached more than $97 \%$ density at $600{ }^{\circ} \mathrm{C}$, whereas the supported membranes had a density of only ca. $70-75 \%$ even at $700{ }^{\circ} \mathrm{C}$ when calcined for $8 \mathrm{~h}$. At $700{ }^{\circ} \mathrm{C}$ the average crystallite size of supported and unsupported membranes was ca. $20 \mathrm{and} 70 \mathrm{~nm}$, respectively. This behaviour is primarily attributed to the decrease in the driving force for sintering due to the stress developed during the constrained sintering of a film attached to a rigid support and to the inhibition of the reorganization process within the film, resulting in lower coordination numbers in supported membranes. Supported membranes showed a higher transformation temperature (slower rate of transformation) than did the unsupported. Supported and unsupported membranes, calcined for $8 \mathrm{~h}$, transformed to ca. $90 \%$ rutile (calculated from Raman spectrum) after calcination at 850 and $650^{\circ} \mathrm{C}$, respectively. This difference in phase transformation behaviour is attributed primarily to the large stress which is developed in a constrained environment owing to the negative volume change during the anatase-rutile transformation.
\end{abstract}

Keywords: Ceramic membrane; Titania; Stability; Phase transformation; Sintering

Ceramic membranes are gaining increased attention because of their high thermal stability compared with organic membranes. When a ceramic membrane is subjected to high temperatures, the following thermally activated processes can occur: viscous and solid-state sintering, crystallization and grain growth resulting in densification, which all lead to changes in pore size and size distribution. The support-membrane interaction is very important in the case of supported membranes, and is discussed in this paper. Certain types of ceramic membrane, especially titania and alumina, can also undergo phase transformations from one crystalline form to another. These transformations are accompanied by a volume change, which enhances the risk of membrane cracking or peeling from the support. The transformation can also cause a drastic reduction in the porosity, and an increase in the mean pore diameter of the membranes. ${ }^{1}$ There have been some studies on the thermal stability of unsupported membranes. ${ }^{1-4,4 a}$ A recent study ${ }^{1}$ on the textural evolution of unsupported titania membranes identified two major causes of textural instability. The most important one was proposed to be the enhanced densification of the rutile phase during the anatase-to-rutile transformation. The second cause of porosity reduction was identified to be anatase crystallite growth. It was also noted that ${ }^{1}$ at lower temperatures (below $350^{\circ} \mathrm{C}$ ) hydrothermal sintering can also play an important role in the porosity reduction of titania membranes. However, very few studies have been carried out concerning the thermal stability of supported membranes. ${ }^{1-4}$ In this paper the phase transformation and sintering behaviour of supported titania layers is reported. Special attention is given to the phase transformation because, for unsupported membranes, as previously noted, enhanced sintering during the phase transform-

† Part 1: K-N. P. Kumar, K. Keizer and A. J. Burggraaf, J. Mater. Chem., 1993, 3, 1141. ation is the major cause of porosity reduction. The results obtained for supported membranes are compared with their unsupported counterparts to check the validity of the common practice of evaluating the textural properties of unsupported membranes and applying the findings directly to the behaviour of supported membranes.

\section{Phase Transformation in Titania System}

Various studies on the anatase-to-rutile transformation with an emphasis to the transformation temperature are discussed in the previous paper. ${ }^{1}$ It should be noted that the anataseto-rutile transformation is a metastable-to-stable transformation and, in a strict sense, there is no real phasetransformation temperature as for an equilibrium reversible transformation. The anatase-rutile transformation temperature reported in the literature, ranges from 400 to $1200{ }^{\circ} \mathrm{C}^{2,5-19}$ The free energy of rutile must be lower, in the anatase-rutile system, at least above $400{ }^{\circ} \mathrm{C}$ since the transformation proceeds at that temperature in the presence of an alkali flux. ${ }^{6}$ The transformation temperature depends on many factors such as the impurities present in anatase, ${ }^{16}$ the method of preparation, ${ }^{10}$ oxygen-to-metal coordination in the precursor, ${ }^{17}$ and oxygen-to-metal bond length in the precursor gel. ${ }^{19}$ Some investigators believe that it also depends on the texture and primary particle size of the anatase. ${ }^{7,10}$ Another important aspect, often neglected, is the effect of residual compressive stress on the solid-state transformation. Ikazaki et al. ${ }^{18}$ reported a lowering of transformation temperature for anatase powder subjected to explosive shock treatment. In this paper the difference in the transformation temperature between supported and unsupported membranes is explained based on the stress developed during sintering and during the phase transformation. 


\section{Importance of Constraint and Coordination on the Thermal Stability of Porous Materials}

The basic causes of thermal instability of porous membranes are crystallite growth and densification. Both processes decrease the surface area and porosity ${ }^{1}$ and may also cause defects in the membrane structure. Sintering in a constrained environment is a topic of great interest. ${ }^{20-22}$ In all these studies the constraint was considered to be an undesirable effect because it retards the densification rate. Moreover, the constraint may cause microcracking in the case of bulk materials sintered in the presence of rigid inclusions. The negative effect of a constraint is more prominent in the case of sintering of films or membranes attached to rigid supports. In these systems the large sintering stresses induce tensile stresses in the film resulting in cracking and delamination of the film from the support. These stresses also have a pronounced effect on the rate of sintering. The retardation of densification and phase transformation rate by the constraint can be conveniently used to produce thermally stable supported titania membranes, and this is discussed further in this paper.

It has been shown by Liniger and $\mathrm{Raj}^{23}$ that the densification rate increases with increasing coordination. Coordination here means the number of the nearest neighbours having actual physical contact. The level of coordination has a direct influence on the actual number of necks formed; this influences sintering and crystallite growth. It is shown later in this paper that one of the possible differences between supported and unsupported membranes is in their particle coordination. The higher the coordination (the larger the sintering pressure) the faster the densification and hence the thermal stability will be poor. The lower coordination in the case of supported membranes, due to the constraint of the support on the reorganization process of the membrane particles, gives them a better thermal stability compared with their unsupported counterpart.

\section{Experimental}

\section{Synthesis of the Sol and the Membranes}

Supported titania membranes and unsupported gel layers were produced from a titania sol synthesized by the hydrolysis of titanium isopropoxide as given in Part 1. Fig. 1 shows schematically the details of the formation processes for supported (SM) and unsupported (USM) membranes. Unsupported gel layers of three different thicknesses were formed by pouring controlled amounts of $0.3 \mathrm{~mol}$ titania sol

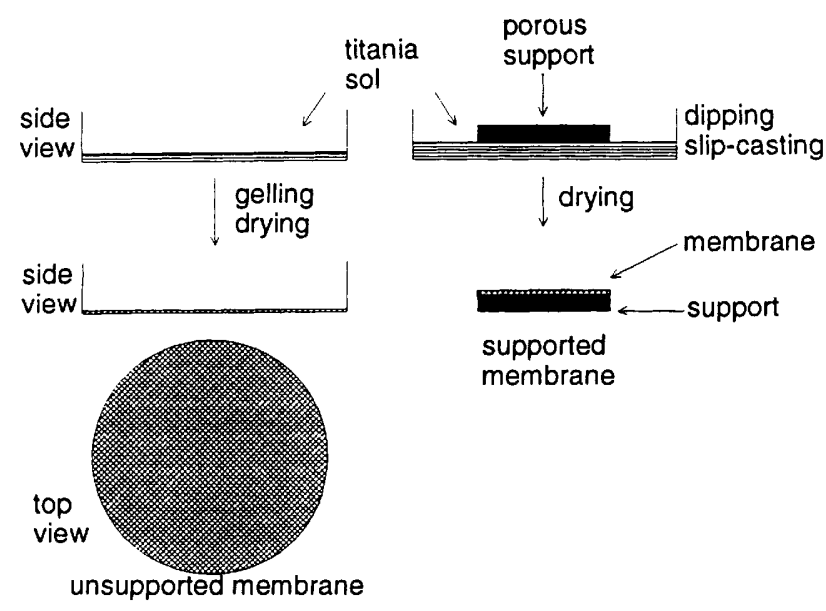

Fig. 1 Different stages involved in the preparation of $(a)$ unsupported (USM) and (b) supported (SM) membranes into a glass petri dish. The excess water in the sol was evaporated by drying at $40{ }^{\circ} \mathrm{C}$ and $60 \%$ relative humidity for $30-40 \mathrm{~h}$ to form a hydrogel layer. The layer was dried and peeled off the glass dish as shown in Fig. 1(a). The thickness of the xerogel layers, after drying, were $7 \mu \mathrm{m}$ (USM-7), $15 \mu \mathrm{m}$ (USM-15) and $50 \mu \mathrm{m}$ (USM-50).

Supported membranes (designated as SM-6) with a thickness of $6 \mu \mathrm{m}$ in the xerogel state were formed on a porous, $2 \mathrm{~mm}$ thick, $\alpha$-alumina support ${ }^{2}$ with an average pore diameter of $160 \mathrm{~nm}$, by dipping one side of the support in the sol for a few seconds as shown in Fig. $1(b)$. The dipping and drying procedure was repeated three times to get a top-layer $6 \mu \mathrm{m}$ thick. The supports were polished to 800 grit finish and cleaned with alcohol before dipping. The membranes were dried at $40{ }^{\circ} \mathrm{C}$ and $60 \%$ relative humidity and calcined at different temperatures. For both supported and unsupported membranes, all calcinations were carried out at a very slow heating rate of $0.2{ }^{\circ} \mathrm{C} \mathrm{min}{ }^{-1}$ up to $300{ }^{\circ} \mathrm{C}$, then cooled to room temperature at a rate of $0.2^{\circ} \mathrm{C} \mathrm{min}^{-1}$. These membranes were calcined further at different temperatures ranging from 450 to $1200{ }^{\circ} \mathrm{C}$ with a heating rate of $1.7^{\circ} \mathrm{C} \mathrm{min}-1$. These were kept at the set temperature for $8 \mathrm{~h}$, and then furnace cooled by switching off the power.

Even though both supported and unsupported gel layers were prepared from the same sol and may contain the same level of impurities, there is a slight difference in their chemistry due to the difference in their formation processes (Fig. 1). For the unsupported membranes all the nitric acid present in the sol will be present in the dried layer. However, the supported membranes will have a lower nitric acid concentration. In this case layer formation is essentially by a slip-casting mechanism so that liquid from the sol is sucked into the support, thereby causing the sol particles to concentrate at the sol/support interface. This hydrogel layer-support system is subsequently dried to form the supported membrane. In this process, the amount of nitric acid present in the sol-hydrogel layer-support region is lower than in the bulk of the sol. However, during drying, nitric acid in the support flows back to the top layer and consequently increases the local acid concentration in the pores. For a better comparison between supported and unsupported layers, some measurements were done on unsupported membranes formed from sols without $\mathrm{HNO}_{3}$ (USM$50-\mathrm{W})$. It is shown that $\mathrm{HNO}_{3}$ has very little influence on the phase-transformation behaviour.

Other possible differences, between supported and unsupported membranes, such as a difference in the levels of organics and hydroxys were not observed. This was confirmed by IR spectroscopy. Moreover, in the case of supported membranes there was no contamination from the $\alpha$-alumina support. This was confirmed by electron probe microanalysis (EPMA) and $X$-ray fluorescence (XRF) results. The detection limits of alumina in titania matrix for EPMA and XRF are ca. $3-5$ atom. $\%$ and $100 \mathrm{ppm}$.

\section{Shrinkage Measurements, Thermal Analysis and X-Ray Diffraction}

It is assumed that the supported membranes do not shrink parallel to their surface. Shrinkage in the thickness of both supported and unsupported membranes was determined by measuring the thickness before and after calcination using SEM. For every temperature a minimum of five samples was measured and the average value was taken. The in-plane shrinkage (linear) of unsupported membranes was measured using a digital micrometer before and after calcination.

Thermal decomposition characteristics were measured with a Polymer Lab. Thermal Science DTA at a heating rate of $10{ }^{\circ} \mathrm{C} \mathrm{min}-1$ in air. The DTA measurements were performed 
using platinum sample cups with $\alpha$-alumina as the reference. All the measurements were carried out in flowing air with a flow rate of $20 \mathrm{ml} \mathrm{min}^{-1}$.

XRD patterns were recorded both for supported and unsupported gel layers with a Philips Diffractometer (PW 1710) using $\mathrm{Cu}-\mathrm{K} \alpha$ radiation in the continuous- and step-scan modes. In the continuous-scan mode, a chart speed of $3 \mathrm{~cm}$ $\min ^{-1}$ was used. In the step-scan mode, a $2 \theta$ range of $24-29^{\circ}$ was scanned in steps of $0.015^{\circ} 2 \theta$ with an interval of $10 \mathrm{~s}$. Further experimental details are given in ref. 1.

\section{Raman Spectroscopy and High-resolution Field Emission Scanning Electron Microscopy (FE-SEM)}

The Raman spectra were recorded using a SPEX-Triplemate spectrometer with microscope attachment (objective 50X; LASER spot size $=2 \mu \mathrm{m}$; focal depth $=5 \mu \mathrm{m}$ ) equipped with an EGG multichannel detector. The laser source was a Spectra Physics $\mathrm{Ar}^{+}$-Laser operating at a wavelength of $514.5 \mathrm{~nm}$, with $25 \mathrm{~mW}$ laser power focused at the spot. Typical measuring times were $1-20 \mathrm{~s}$.

In this study, Raman spectroscopy was used as the main tool to compare the supported and unsupported layers. XRD is not a convenient technique for studying supported membranes because $\mathrm{X}$-rays penetrate through the top membrane layer so that a convoluted diffraction pattern of both alumina (support) and titania results, whereas Raman spectra give only information from the top layer.

Titania membranes were subjected to high-resolution scanning electron microscopic (FE-SEM) study using a Hitachi S-900 system. ${ }^{1}$

\section{Permporometry}

This is a relatively new technique to measure the active poresize distribution of supported membranes. ${ }^{24-27}$ It is based on the fact that when a porous system is exposed to a mixture of a non-condensable and a condensable gas, the last one will condense in the pores depending on its partial pressure. When the partial pressure is increased from zero, larger and larger pores will be filled with the gas (capillary condensation) and all the pores will be filled when the relative pressure reaches 1. The active pore-size distribution is measured by allowing a non-condensable gas to permeate through the membrane at different partial pressures of the condensable gas.

In the present case cyclohexane was used as the condensable gas and $\mathrm{N}_{2}$ as the carrier gas. Gas permeation was measured using $\mathrm{O}_{2}$. It should be noted that a second non-condensable gas (in the present case, $\mathrm{O}_{2}$ ) is used because $\mathrm{N}_{2}$ is present on both sides of the membrane. Measurements were carried out in the desorption mode. When the partial pressure of cyclohexane is 1 , all the pores will be filled and the oxygen flux will be zero. By lowering the partial pressure of cyclohexane, more and more pores will be emptied and therefore the $\mathrm{O}_{2}$ flux increases. Details of the calculation of the pore size distribution are given elsewhere. $^{27}$

\section{Results and Discussion}

\section{Thermal Analysis}

DTA traces of USM-15 and USM-50 are illustrated in Fig. 2. There are two endothermic peaks, one at $95^{\circ} \mathrm{C}$ and one at $350{ }^{\circ} \mathrm{C}$. The first peak represents the removal of physically adsorbed water from pores of the gel. The second peak represents the dehydroxylation reaction and the decomposition of residual nitrates. ${ }^{1}$ There is a third peak in the range 580-600 ${ }^{\circ} \mathrm{C}$, corresponding with the enthalpy released during

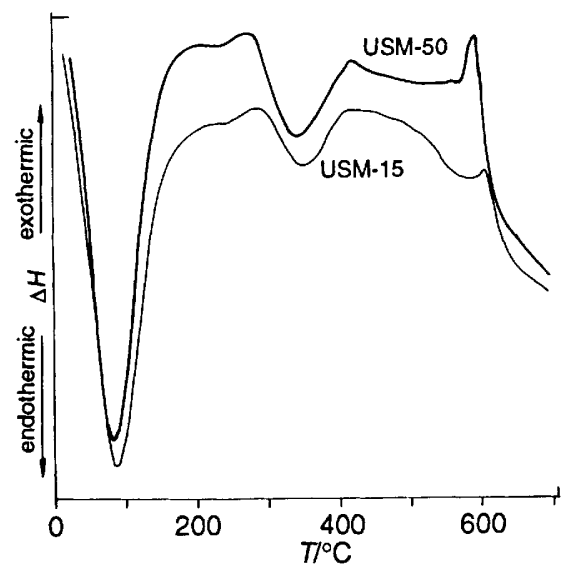

Fig. 2 DTA traces of USM-50 and USM-15

the anatase-to-rutile phase transformation. The details about the thermal behaviour of sol-gel derived titania membranes are given elsewhere. ${ }^{1}$ We clearly see a small shift of $c a .15^{\circ} \mathrm{C}$ in the peak corresponding to the phase transformation temperature. Furthermore, the area under the peak is larger in the case of thicker membranes, although all the thermal analyses were done with the same sample size. This shows that the processes of phase transformation and recrystallization are more sluggish for thinner membranes.

\section{X-Ray Diffraction of Unsupported Membranes}

Fig. 3 illustrates the XRD pattern that was recorded in the continuous-scan mode, for USM- 50 heated at $600{ }^{\circ} \mathrm{C}$ for $8 \mathrm{~h}$. All peaks correspond to pure rutile. This is in agreement with the thermal analysis results discussed above. XRD. pattern in the step-scan mode showed the presence of small amounts of anatase in the $600{ }^{\circ} \mathrm{C}$ heated samples. Fig. 4 illustrates the step-scan results for USM-15 and USM-50. We clearly see a relatively large peak corresponding to the (101) reflection of anatase in the USM-15 spectrum compared with that of USM-50. The diffraction pattern of USM-7 was similar to that of USM-15. The rutile content is calculated on the basis of the following equation: ${ }^{28}$

$$
W_{\mathrm{R}}=1 /\left[1+0.8\left(I_{\mathrm{A}} / I_{\mathrm{R}}\right)\right]
$$

$W_{\mathrm{R}}$ is the weight fraction of rutile and $I_{\mathrm{A}}$ and $I_{\mathrm{R}}$ are the X-ray intensities of the (101) and (110) reflections. In Table 1 , the phase composition of unsupported membranes of different

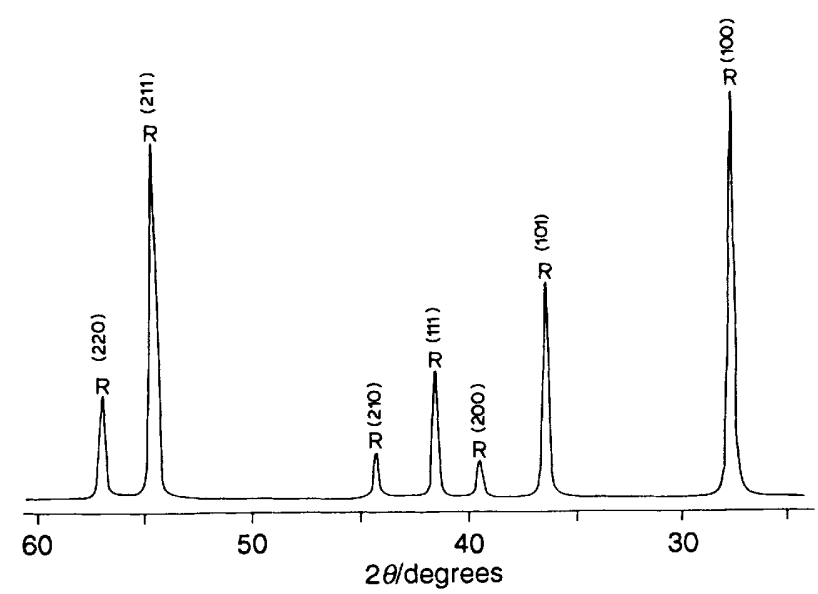

Fig. 3 XRD spectrum of USM-50 


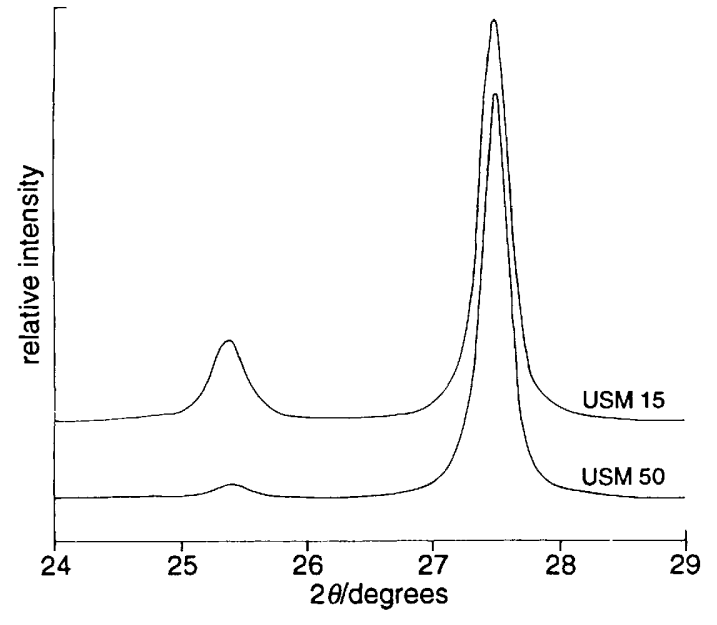

Fig. 4 Step-scan spectra of USM-50 and USM-15 calcined at $600{ }^{\circ} \mathrm{C}$

Table 1 Weight percentage of rutile present in unsupported membranes of different thicknesses

\begin{tabular}{lccc}
\hline & \multicolumn{3}{c}{ weight of rutile (\%) } \\
\cline { 2 - 4 } $\begin{array}{l}\text { calcination } \\
\text { temperature } /{ }^{\circ} \mathrm{C}\end{array}$ & thin $(7 \mu \mathrm{m})$ & thin $(15 \mu \mathrm{m})$ & thick $(50 \mu \mathrm{m})$ \\
\hline 500 & $40 \pm 4$ & $45 \pm 5$ & $50 \pm 4$ \\
600 & $90 \pm 3$ & $92 \pm 4$ & $95 \pm 2$ \\
700 & 100 & 100 & 100 \\
\hline
\end{tabular}

thicknesses is presented. After calcination at $700{ }^{\circ} \mathrm{C}$ for $8 \mathrm{~h}$, all the membranes contain almost $100 \%$ rutile.

\section{Raman Spectroscopy}

Anatase and rutile give distinct and characteristic Raman spectra. In addition, Raman spectra will give information about transformations occurring at or very near to the surface such as surface residual stress-controlled nucleation. The most important capability is that the measurement of Raman intensities of different phases can be used to quantify the amount of phase present without much standardization. ${ }^{29}$ In order to avoid band-broadening effects such as difference in crystallite sizes, integrated intensities of the Raman bands were used for the quantitative calculations.

Raman spectra that were recorded for SM-6 and USM-50 (the spectrum of USM-50-W is identical to that of USM-50) are shown in Fig. 5(a) and $(b)$. For clarity the origin is shifted along the vertical axis for curve $(b)$. The samples were heated at $700{ }^{\circ} \mathrm{C}$ for $8 \mathrm{~h}$ at the same time in the same furnace. Typically, the supported membranes show an anatase spectrum. All bands marked ( $\nabla$ ) belong to anatase while those marked ( belong to rutile. The crystallographic unit cell of anatase is body-centred (space group $D_{4 h},{ }^{19} I 4_{1} / a m d$ ) and contains two primitive unit cells, each of which contains two formula units of $\mathrm{TiO}_{2}$. According to factor group analysis, ${ }^{9}$ six modes, $\left(\mathrm{A}_{1 \mathrm{~g}}+2 \mathrm{~B}_{1 \mathrm{~g}}+3 \mathrm{E}_{\mathrm{g}}\right)$ are Raman active. In the present case, all of the six bands are observed. Only the first overtone of the first-order mode with $\mathbf{B}_{1 \mathrm{~g}}$ at $398 \mathrm{~cm}^{-1}\left(796 \mathrm{~cm}^{-1}\right)$ is not observed. However, the observed bands have a slight shift with respect to the published results, ${ }^{9}$ which is probably due to the residual stress in the supported membrane. ${ }^{20} \mathrm{~A}$ difference in oxygen stoichiometry, ${ }^{30,31}$ if any, may also cause shifts in Raman bands.

In Fig. 5 [curve $(b)$ ], a Raman spectrum of an unsupported titania layer (USM-50) is illustrated. This material is predominantly rutile at this temperature. The rutile structure has two titania molecules in the unit cell with the space group $D_{4 \mathrm{~h}}{ }^{14}$

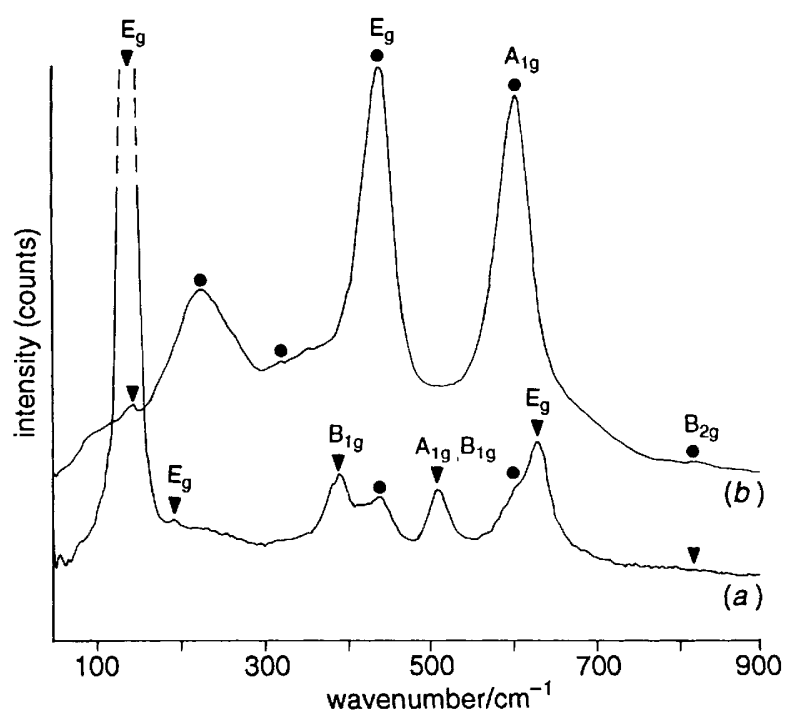

Fig. 5 Raman spectra of (a) SM-6 and (b) USM-50 calcined at $700{ }^{\circ} \mathrm{C}$ for $8 \mathrm{~h}$

$\left(P 4_{2} / m n m\right){ }^{9}$ According to group theory, four modes are Raman active, $\left(A_{1 g}+B_{1 g}+B_{2 g}+E_{g}\right)$. Similar to the anatase spectrum, the rutile spectrum also has slight band shifts. The weak band at $142 \pm 2 \mathrm{~cm}^{-1}$ is probably due to traces of anatase in the sample. ${ }^{24}$ The relatively strong band at $230 \pm 3 \mathrm{~cm}^{-1}$ is not included in the set of first-order bands predicted by group theory. ${ }^{9}$ All the other bands correspond to the predicted bands for the rutile system. The spectrum of an unsupported layer without $\mathrm{HNO}_{3}$ (USM-50-W) is identical to the one illustrated in Fig. 6 [curve $(a)$ ]. This observation clearly shows that the difference in the phase-transformation behaviour of supported and unsupported titania membranes is due to something other than the slight difference in chemistry.

Fig. 6 illustrates the Raman spectra of USM-50 and USM15 heated at $600{ }^{\circ} \mathrm{C}$ for $8 \mathrm{~h}$. The thinner membrane has only relatively less developed rutile bands compared with the thicker one. Along with XRD, Raman spectroscopy also confirms clearly the thickness dependence of phasetransformation behaviour in unsupported membranes. It should be noted that the difference between unsupported membranes of different thicknesses is small compared with

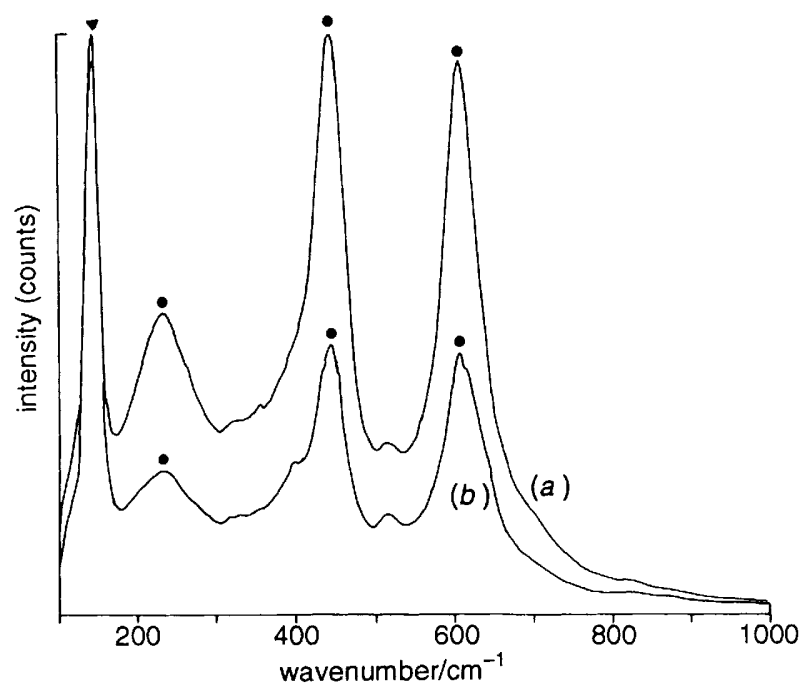

Fig. 6 Raman spectra of unsupported membranes (a) USM-50 and (b) USM-15 after calcining at $600^{\circ} \mathrm{C}$ for $8 \mathrm{~h}$ 
the difference between supported and unsupported membranes of comparable thickness.

Fig. 7 shows the fraction of the rutile phase, calculated from Raman intensities, that is present in the membranes after calcination at different temperatures for $8 \mathrm{~h}$. The fraction of rutile present $\left(C_{\mathrm{R}}\right)$ was calculated on the basis of the following semi-quantitative equation: ${ }^{29}$

$$
C_{\mathrm{R}}=K I_{\mathrm{R}}^{447} /\left(I_{\mathrm{R}}^{447}+I_{\mathrm{A}}^{144}\right)
$$

$K$ is a constant which is approximately equal to unity while $I_{\mathrm{R}}^{447}$ and $I_{\mathrm{A}}^{144}$ are the integrated Raman intensities of the $447 \mathrm{~cm}^{-1}$ band of rutile and the $144 \mathrm{~cm}^{-1}$ band of anatase. The area of analysis was a circle of $10 \mu \mathrm{m}$ diameter, corresponding to $c a .10^{9}$ grains (if we assume the grain size of titania to be $c a .10 \mathrm{~nm}$ ). The actual grain size increases from $c a .6 \mathrm{~nm}$ (in the as-precipitated state) to $c a .70 \mathrm{~nm}$ after treatment at $600{ }^{\circ} \mathrm{C}$.

Fig. 7(a), (b) and (c) give plots for unsupported membranes 50,15 , and $7 \mu \mathrm{m}$ thick, respectively. The $50 \mu \mathrm{m}$ thick membrane has a slightly larger transformation rate than the thinner ones $(15$ and $7 \mu \mathrm{m})$. The supported membrane [Fig. $7(d)]$ shows a considerably higher transformation temperature compared with the unsupported membranes.

\section{Nanostructural Evolution}

Nanostructural changes of both supported and unsupported membranes calcined at different temperatures were observed to compare the porosity reduction and primary crystallite growth. Both supported and unsupported membranes were prepared from sol containing PVA and HPC as given elsewhere. ${ }^{2}$ Fig. 8 shows the field emission scanning electron (FESEM) micrographs of the membranes heated at $450{ }^{\circ} \mathrm{C}$. We clearly observe that the unsupported membrane [Fig. 8(a)] is much denser, with a porosity of $c a$. 15-20\%, than the supported membrane with a porosity of ca. 25-30\% [Fig. 9(b)]. The sizes of the primary crystallites are more or less the same for both supported and unsupported membranes, in the range $15-20 \mathrm{~nm}$, and both are pure anatase. After treatment at $600{ }^{\circ} \mathrm{C}$ the difference between the unsupported [Fig. $\left.9(a)\right]$ and supported membranes [Fig. $9(b)]$ has become larger. There is a clear difference between the primary crystallite sizes in supported and unsupported membranes. The unsupported membrane contains more than $95 \%$ rutile. The larger crystallites of $c a .45 \mathrm{~nm}$ average size are rutile. The smaller anatase crystallites are still in the range of $20 \mathrm{~nm}$. The residual porosity in the unsupported membrane is $<3 \%$. This drastic reduction in porosity is due to the enhanced sintering during the phase transformation. ${ }^{1}$ During phase transformation atoms are very mobile and the self diffusion coefficients are high. At $600^{\circ} \mathrm{C}$

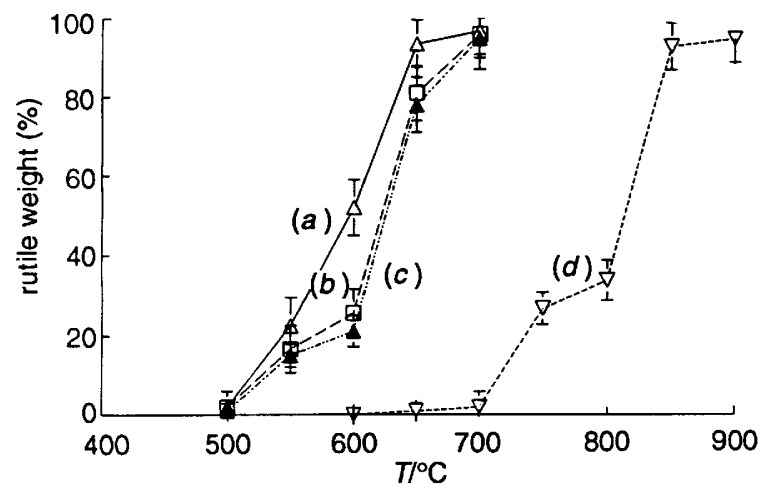

Fig. 7 Fraction of rutile present $v$ s. calcination temperature of titania membranes: (a) USM-50, (b) USM-15, (c) USM-7 and (d) SM-6 supported membranes retain a porosity of $c a .25-30 \%$ and they still consist of anatase with an average crystallite size of $c a .19 \mathrm{~nm}$. The porosity was calculated from the micrographs by taking a surface average, which is a good approximation for comparison. Even at $700{ }^{\circ} \mathrm{C}$ the nanostructure of supported membranes [Fig. $10(b)$ ] is not very different from the $600{ }^{\circ} \mathrm{C}$ sample. At $700{ }^{\circ} \mathrm{C}$ the unsupported membrane is almost dense with a grain size of $c a .70 \mathrm{~nm}$. The supported membrane still has a porosity of $c a$. $25-30 \%$ and the crystallite size is $c a .20 \mathrm{~nm}$. The supported membrane consists mainly of anatase.

The pore size distribution (from permporometry) of a supported membrane calcined at $500^{\circ} \mathrm{C}$ for $8 \mathrm{~h}$ is given Fig. 11. At this temperature and soaking time the porosity of unsupported membranes has completely disappeared. From Fig. 11 it is clear that the supported membrane is still porous and has an average pore radius of $c a .5 \mathrm{~nm}$, whereas unsupported membranes which underwent the same thermal treatment had practically no porosity (immeasurably small). It should be noted that the pore size obtained from permporometry is the average size of the narrowest portions of a given set of individual pores. Therefore, it is difficult to obtain the actual porosity from these data. It is important to note that in any case the actual porosity of the supported membranes is higher than that of the unsupported one which underwent the same type of heat treatment.

Fig. 12 gives the shrinkage data for the membranes calcined at different temperatures for $8 \mathrm{~h}$. The top curve (IPUSM) gives the in-plane shrinkage of the unsupported membranes. The middle (TSM) and the bottom (TUSM) curves give the shrinkage in the thickness direction of supported and unsupported membranes. It can be seen from the figure that for the unsupported membranes there is only a very small shrinkage in the thickness direction (TUSM), less than $5 \%$ at $600{ }^{\circ} \mathrm{C}$. Almost all the shrinkage takes place in the plane (IPUSM; in-plane shrinkage) of the membrane and the total volume shrinkage is $c a .35 \pm 5 \%$. A similar result has been reported by Garino for silica films. ${ }^{32}$ In the thickness direction (TSM) the supported membranes had a shrinkage of $c a .18 \%$ at $600{ }^{\circ} \mathrm{C}$ (no shrinkage in the in-plane direction). The total volume shrinkage of supported membranes is less than that of the unsupported membranes. This result is not in agreement with the result of Garino, ${ }^{32}$ he found that the shrinkage in the thickness direction is more for supported layers compared to the unsupported ones. This disagreement may be because of the following differences. (1) The final microstructure of supported and unsupported membranes are different in our case; at $600{ }^{\circ} \mathrm{C}$ the unsupported membrane is more or less completely dense whereas the supported one retained a porosity of $c a .30 \%$. As published by Garino ${ }^{32}$ both supported and unsupported silica films reached almost the same density. (2) In the silica system densification is via a viscous sintering mechanism, whereas in titania it is via solid-state sintering. Moreover, the final nanostructures of both (supported and unsupported) films are more or less the same in the case of silica films. ${ }^{32}$ From the above results it is expected that starting from the drying stage the arrangement and packing of the particles in supported and unsupported membranes are different. It is clear from the above discussions that porosity reduction behaviour of supported and unsupported membranes are very different and the porosity reduction in supported membranes is effectively retarded by the support constraint.

Another important parameter which affects the densification and crystal growth behaviour is the average coordination number of the particles. Here coordination number refers to the number of real contact points between a certain particle and its neighbours. In the case of unsupported membranes 
(a)

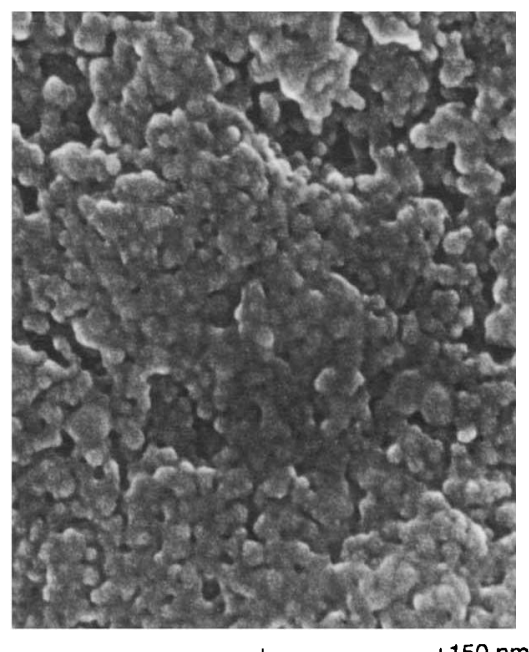

(b)

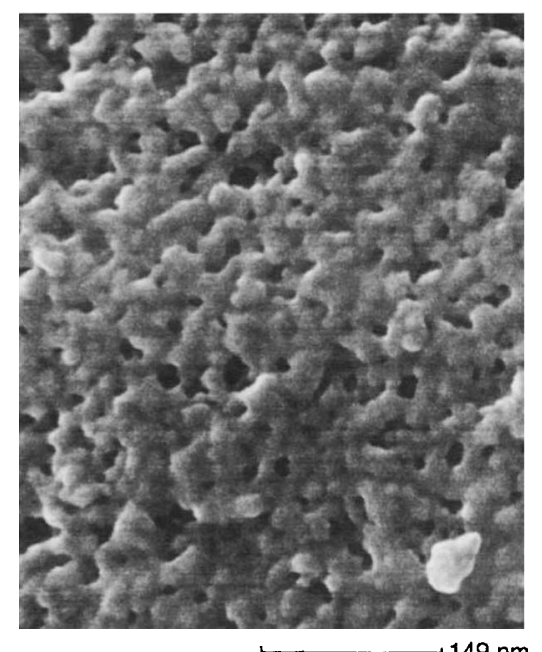

Fig. 8 FE-SEM micrographs of (a) unsupported and (b) supported membranes heated at $450{ }^{\circ} \mathrm{C}$

(a)

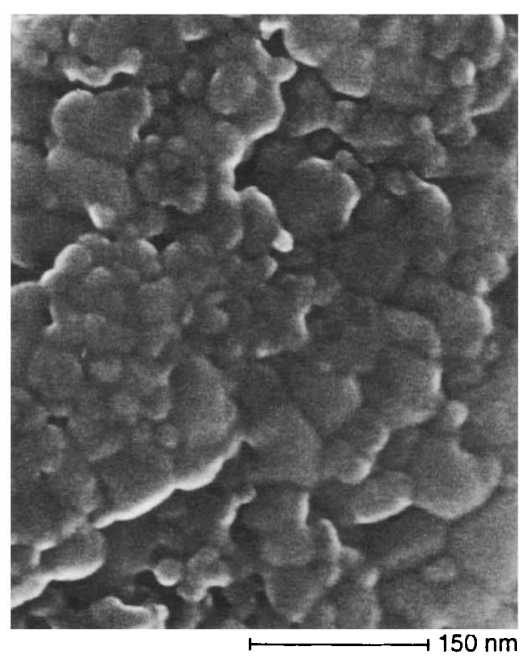

(b)

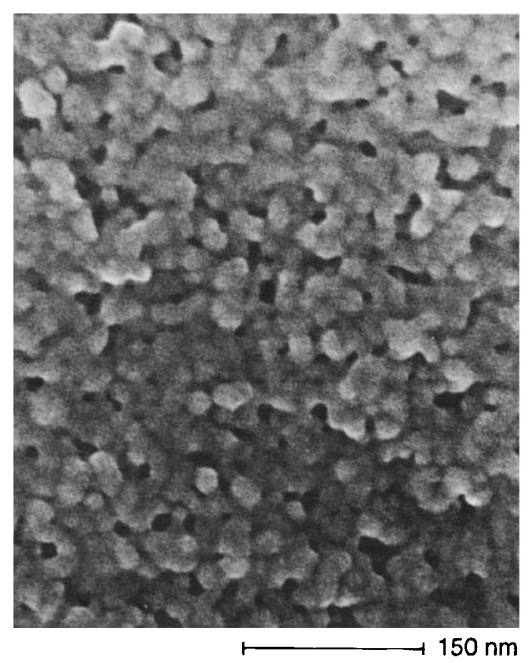

Fig. 9 FE-SEM micrographs of $(a)$ unsupported and $(b)$ supported membranes heated at $600{ }^{\circ} \mathrm{C}$

(a)

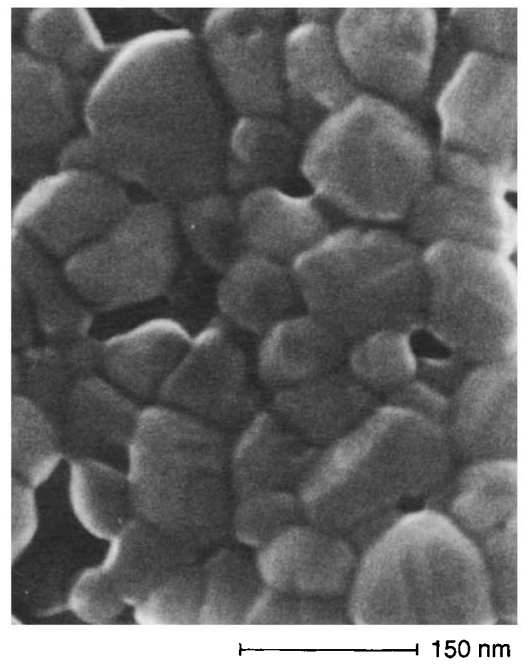

(b)

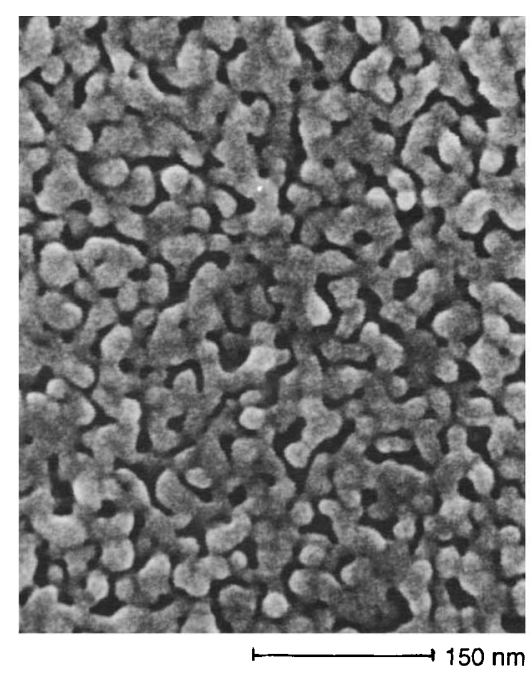

Fig. 10 FE-SEM micrographs of $(a)$ unsupported and $(b)$ supported membranes heated at $700{ }^{\circ} \mathrm{C}$ 


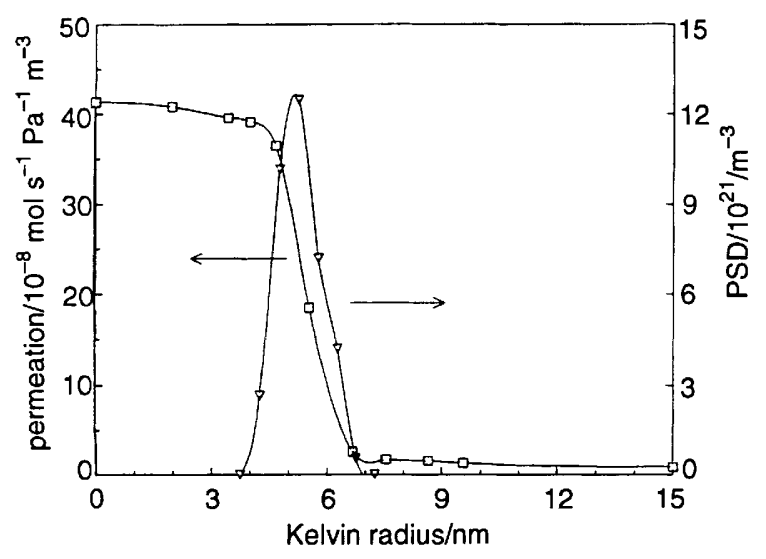

Fig. 11 Permporometry trace of supported titania membranes calcined at $500{ }^{\circ} \mathrm{C}$ for $8 \mathrm{~h}$

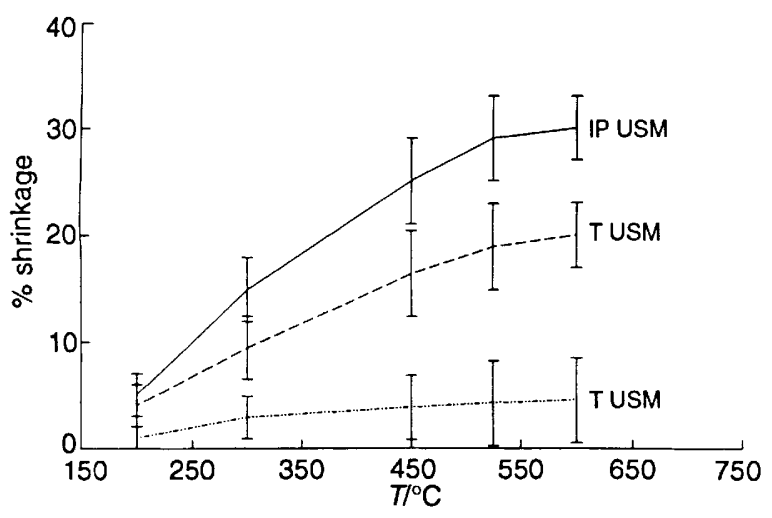

Fig. 12 Shrinkage (in thickness) of supported and (in thickness and in in-plane direction) of unsupported titania membranes calcined at different temperatures for $8 \mathrm{~h}$

the packing and hence the average coordination number is higher than that of the supported membranes. There are two processes which influence the packing and hence the coordination number. The first one is the drying processes. During drying the particles in the supported membrane are hindered from rearrangement (ordering) and packing by the support constraint compared with the unsupported membranes. ${ }^{4 a}$ The second process is the initial stage of sintering, for which the necessary reorganization is again partly inhibited by the particle-support interaction. Both processes result in a relatively low number of physical contact points and consequently a lower activity in sintering and crystallite growth. The FESEM micrographs of the unsupported and supported membranes given in Fig. $8(a)$ and $(b)$ and the shrinkage data in Fig. 12 show that at any given temperature a supported membrane is more porous than an unsupported one. A decrease in porosity is normally associated with an increase in coordination number, in particular for membranes heattreated at lower temperatures, because at this stage the particle sizes in supported and unsupported membranes will be comparable. The decrease in sintering rate with decrease in coordination number is in agreement with the results reported by Liniger and $\mathrm{Raj}^{23}$ They have studied the densification behaviour of a model consisting of two-dimensional arrays of glass spheres. They found that the higher the coordination the better the densification. This substantiates the explanation given for the poor densification of supported membranes.
Stress Developed during the Anatase-to-rutile Phase Transformation

During the anatase-to-rutile transformation there is a volume decrease of $c a .8 \%$. In the case of supported membranes this volume change is prevented by the rigid support, assuming a very good adherence of the particles and the support, as shown in Fig. 13. The in-plane stress, $\sigma_{x}$, developed due to this volume change can be expressed as: ${ }^{33}$

$$
\sigma_{x}=(1 / 3) \times[E /(1-v)] \times(\Delta V / V)
$$

where $E$ is Young's modulus, $v$ is Poisson's ratio and $(\Delta V / V)$ is the volumetric strain, which is $c a$. 0.08. Assuming $E=$ $50 \mathrm{GPa}$ for porous titania ( $\mathrm{ca} .30 \%$ porosity) we obtain a value of $1800 \mathrm{MPa}$ for the in-plane stress. The effective stress will be less than $1800 \mathrm{MPa}$ because of stress relaxation due to creep, and this stress should be considered as an upper limit.

\section{Effect of Stress on the Equilibrium Transformation Temperature of Supported Membranes}

During the phase transformation, supported gel layers try to shrink and consequently experience a two-dimensional tensile stress field. A portion of this stress may be relaxed due to creep. Another cause of stress, even though minor, is the 'residual' tensile stress present in the membrane top layer after drying. ${ }^{34-37}$ Based on the above facts, a thermodynamic calculation, using the Clapeyron equation, ${ }^{38}$ can be performed to estimate the change of the phase-transformation temperature due to the two-dimensional tensile stress field in the supported membranes. However, it should be noted that, in a strict sense, the Clapeyron equation is only valid for equilibrium transformations from a stable phase to another stable phase. But as an approximate analysis, assuming the system is not far from equilibrium, we can apply this to the anatase to rutile (metastable-to-stable) transformation.

From the Clapeyron equation, ${ }^{38}$ the change in the phasetransformation temperature, $\Delta T$, can be written as

$$
\Delta T=(T \Delta V / \Delta H) \Delta P
$$

where $T$ is the equilibrium transformation temperature, assumed to be $700{ }^{\circ} \mathrm{C} ; \Delta V$ is the volume change accompanying the anatase-rutile transformation, $-1.73 \mathrm{~cm}^{3} \mathrm{~mol}^{-1} ; \Delta H$ is the enthalpy of transformation, $6.51 \times 10^{3} \mathrm{~J} \mathrm{~mol}^{-1,39} \Delta P$ is the pressure, and in the present case this is predominantly the stress developed during the anatase to rutile transformation, ca. $1800 \mathrm{MPa}$. Applying the value of the hydrostatic tensile stress component $1200 \mathrm{MPa}[1800 \times(2 / 3)]$ in eqn. (4) we obtain a maximum $\Delta T$ value of $\mathrm{ca} .300^{\circ} \mathrm{C}$. This is in reasonable agreement with the observed shift in the transformation temperature. The contribution of the temperature shift from the residual drying stress, which is $c a .40 \mathrm{MPa}$ in the dried stage,,$^{34-37}$ was calculated to be $c a .5^{\circ} \mathrm{C}$, which is insignificant compared with the shift calculated using the transformation stress.

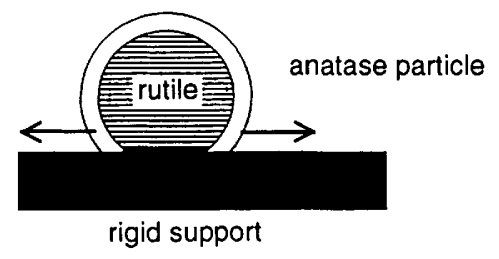

Fig. 13 Schematic representation of the nucleation of rutile in a constrained environment 


\section{Effect of Stress, Coordination and Packing on Nucleation}

The anatase-rutile polymorphic transformation is a firstorder irreversible metastable-to-stable transformation. In the anatase-rutile system, at all temperatures rutile is expected to have a lower free energy compared to anatase. From this we see that the most important aspect in the transformation should be the process of overcoming the activation energy barrier. A consideration of the kinetics of the transformation may be helpful in describing the phase-transformation behaviour. According to the temperature-free energy diagram, rutile is thermodynamically more stable than anatase at any given temperature. Of the two stages of transformation (nucleation and growth), nucleation is the more important in the case of solid-state transformations with a volume change, but without the possibility of any plastic or viscous flow of either the matrix phase (anatase) or the transformed phase. The equation for the energy balance for nucleation ${ }^{40,41}$ can be written as:

$$
G=-g_{v} \Delta V+g_{s} \Delta S+g_{\text {str. }} \Delta V+g_{\text {stress }} \Delta V
$$

where $G$ is the total Gibbs free-energy change, $\Delta V$ and $\Delta S$ are the volume and surface area of the nucleus formed. $g_{v}$ is the difference in the volume free energies of the two phases; in this case this is negative. $g_{s}$ is the energy needed to create a new interface, and is always positive. $g_{\text {str. }}$ is the strain energy term due to the difference between the volume of the phases, and is also always positive. $g_{\text {stress }}$ is the term representing the residual stresses present in the material. The sign of $g_{\text {stress }}$ depends upon the type of the residual stress field, compressive or tensile. Eqn. (5) can be represented in terms of the radius of the nucleus:

$$
G=-A r^{3}+B r^{2}+C r^{3}+D r^{3}
$$

where $A, B, C$, and $D$ are constants proportional to the corresponding terms in eqn. (5). The nucleation followed by growth will proceed when $r$ reaches the critical value $r_{\mathrm{c}}$ (i.e. when $G$ becomes maximum, $r=r_{c}$ ).

When $G$ is a maximum, $\mathrm{d} G / \mathrm{d} r=0$, so that we obtain the relation:

$$
\begin{gathered}
-3 A r_{\mathrm{c}}^{2}+2 B r_{\mathrm{c}}+3 C r_{\mathrm{c}}^{2}+3 D r_{\mathrm{c}}^{2}=0 \\
\text { where } r_{\mathrm{c}}=(2 / 3) B /(A-C-D)
\end{gathered}
$$

For a given system, at a given temperature and pressure, the values of $A$ and $B$ are constant. In this situation, the nucleation rate is totally dependent on $C$ and $D$. The contribution of $D$ is negligible because the residual stress due to drying, if any, is not significant at the phase-transformation temperature. Eqn. (8) becomes

$$
r_{\mathrm{c}}=(2 / 3) B /(A-C)
$$

As discussed earlier, in the case of supported membranes (SM-6) the top-layer experiences a large tensile stress field due to the volume change during the anatase-to-rutile transformation, compared with the unsupported counterpart. Since the volume change in the transformation is negative, a tensile stress field will oppose the transformation. Therefore, the parameter $C$ in eqn. (9) will be positive. This effect in turn gives a larger value for $r_{\mathrm{c}}$ and the result is a slower rate of transformation due to a slower rate of nucleation, with an increase in $C$. This is in agreement with the Clapeyron analysis.

A possible reason for the difference in the phasetransformation behaviour of unsupported membranes of different thickness is given below. It has been indicated that ${ }^{1}$ the anatase-to-rutile transformation is probably a surface nucleation controlled transformation. This surface transformation induces a compressive stress in the bulk of the mem- brane. This in turn increases the negative value of $C$ [eqn. (9)]. This effect is more important in thicker membranes and can also explain the fact that thicker unsupported membranes transform faster than the thinner ones.

Effective coordination can also influence the kinetics of phase transformation. It can either exert an influence in the nucleation stage, if $r_{\mathrm{c}}$ of rutile is larger than the primary crystallite size of the transforming anatase, or in the growth stage. From the FE-SEM micrographs (Fig. 8-10) and from the grain growth studies it can be seen that the rutile crystallites are at least $4-5$ times larger than the anatase crystallites just after transformation. ${ }^{1,42}$ Thus, it may be possible that the critical nucleus size of rutile is larger than the primary crystallite size of anatase. If this is true, more than one anatase crystallite is required for forming a single rutile nucleus. Therefore the number of nearest neighbours in actual contact (coordination number) has some influence on the nucleation rate. The growth rate is affected in the same way. So inhibition of reorganization of the primary particles and thereby decreasing the coordination number is a mechanism which supplements the slower rate of anatase-to-rutile phase transformation in supported membranes caused by the stress developed due to the negative volume change during the transformation.

\section{Conclusions}

(1) Unsupported membranes retained a porosity of only $c a$. $15-20 \%$ at $450{ }^{\circ} \mathrm{C}$, whereas the supported membranes showed a porosity of ca. $25-30 \%$ even at $700^{\circ} \mathrm{C}$ after a calcination time of $8 \mathrm{~h}$. This behaviour may be attributed to the decrease in the driving force for sintering due to the stress developed during the constrained sintering of a film attached to a rigid support, and also the fact that the particle rearrangement and packing in supported membranes is prevented by the support and this may result in a lower coordination number for the primary particles in the supported membranes compared with those in the unsupported. (2) Supported membranes showed a higher transformation temperature (slower rate of transformation) than unsupported ones, which have already transformed to more than $90 \%$ of rutile after calcination at $650{ }^{\circ} \mathrm{C}$ for $8 \mathrm{~h}$, whereas the supported membranes had undergone the same level of transformation only after treatment at $c a .850{ }^{\circ} \mathrm{C}$. The phase content was calculated from the Raman spectrum. (3) The common practice of evaluating the textural properties of unsupported membranes and using them to understand the properties of supported membranes underestimates the textural stability of supported membranes. This is because in the case of supported membranes the rigid support has an important contribution in stabilizing the porous texture (porosity, pore size and crystallite size) of the membrane top-layer. Therefore at any given temperature, supported membranes will have smaller pores and higher porosity compared with the unsupported membranes.

\section{References}

1 K-N. P. Kumar, K. Keizer and A. J. Burggraaf, J. Mater. Chem., 1993, 3, 1141

2 V. T. Zaspalis, W. van Praag, K. Keizer, J. R. H. Ross and A. J. Burggraaf, J. Mater. Sci., 1992, 27, 1023.

3 A. Larbot, J. P. Fabre, C. Guizard and L. Cot, J. Am. Ceram. Soc., 1989, 72, 257.

4 (a) R. J. R. Uhlhorn, Ph.D Thesis, University of Twente, Enschede, The Netherlands, 1990. (b) A. F. M. Leenaars, K. Keizer and A. J. Burggraaf, J. Mater. Sci., 1984, 19, 1077.

5 E. F. Heald and C. W. Weiss, Am. Mineral., 1972, 57, 10 
6 F. C. Kracek, U.S. Geol. Surv., 1963, 1144-D, 81.

7 R. D. Shannon and J. A. Pask, J. Am. Ceram. Soc., 1965, 48, 391.

8 A. I. Sheinkman, V. A. Tyumentsev and A. A. Fotiev, Izv. Akad. Nauk SSSR, Neorg. Mater., 1984, $20,1692$.

9 U. Balachandran and N. G. Eror, J. Solid State Chem., 1982, 42, 276.

10 Y. Iida and S. Ozaki, J. Am. Ceram. Soc., 1961, 44, 120.

11 H. Knoll and U. Kühnhold, Naturwissenschaften, 1957, 44, 394.

12 A. W. Czanderna, C. N. R. Rao and J. M. Honing, Trans. Faraday Soc., 1958, 54, 1069.

13 C. N. R. Rao, Can. J. Chem., 1961, 39, 498.

14 F. Dachille, P. Y. Simens and R. Roy, Am. Mineral., 1968, 53, 1929.

15 A. Matthews, Am. Mineral., 1976, 612, 419.

16 R. D. Shannon, J. Appl. Phys., 1964, 35, 3414.

17 J. Livage, personal communication, 1989.

18 F. Ikazaki, K. Uchida, A. Goto, M. Kawamura and S. Fujiwara, Funtai Kogaku Kaishi, 1983, 20, 717.

19 B. E. Yoldas, J. Mater. Sci., 1986, 21, 1087.

20 G. W. Scherer, J. Am. Ceram. Soc., 1987, 70, 719.

21 R. K. Bordia and R. Raj, J. Am. Ceram. Soc., 1985, 68, 287.

22 R. Raj and R. K. Bordia, Acta Metall., 1984, 32, 1003.

3 E. G. Liniger and R. Raj, J. Am. Ceram. Soc., Part C 1988, 71, 408.

A. Mey-Maron and M. Katz, J. Membrane Sci., 1986, 27, 119.

M. Katz and G. Baruch, Desalination, 1986, 58, 199.

26 F. P. Cuperus, D. Bargeman and C. A. Smolders, J. Membrane Sci., 1992, 71, 57.

27 G. Z. Cao, J. Meijerink, H. W. Brinkman, K. J. de Vries and A. J. Burggraaf, J. Membrane Sci., 1993, in the press.

28 R. A. Spurr and H. Myers, Anal. Chem., 1957, 29, 760.

29 D. R. Clarke and F. Adar, J. Am. Ceram. Soc., 1990, 65, 284.

30 J. C. Parker and R. W. Siegel, J. Mater. Res., 1990, 5, 1296.
31 C. A. Melendres, A. Narayanaswammy, V. A. Maroni and R. W. Siegel, J. Mater. Res., 1989, 4, 1246.

32 T. J. Garino, in Better Ceramics Through Chemistry IV, MRS Symposium Proceedings, ed. B. J. J. Zelinski, C. J. Brinker, D. E. Clark and D. R. Ulrich, 1990, vol. 180, p. 497.

33 J. M. Gere and S. P. Timoshenko, Mechanics of Materials, 3rd edn. Chapman and Hall, London, 1991.

34 J. H. L. Vonken, C. Lijzenga, K. P. Kumar, K. Keizer, A. J. Burggraaf and B. C. Bonekamp, J. Mater. Sci., 1992, 27, 472.

35 K-N. P. Kumar, K. Keizer and A. J. Burggraaf, J. Mater. Sci., submitted.

36 K. P. Kumar, V. T. Zaspalis, C. Lijzenga, K. Keizer and A. J. Burggraaf, Presented at the Sixth International Work shop on Glasses and Ceramics from gels, Sevilla (Spain) Oct. 6-11, 1991.

37 V.T. Zaspalis, unpublished results, 1992.

38 R. A. Swalin, The Thermodynamics of Solids, Wiley, New York, 1972.

39 JANAF Thermochemical Tables, ACS, AIP, NBS, Part II, ed. M. W. Chase Jr., C. A. Davies, J. R. Downey Jr., D. J. Frurip R. A. McDonald and A. N. Syverud, 1985, vol. 14.

40 A. C. Zettlemoyer, Nucleation, Marcel Dekker, New York, 1969, p. 405.

41 J. W. Christian, The Theory of Transformations in Metals and Alloys: Part I, Pergamon Press, Oxford, 1975.

42 M. J. Mayo, Presented at the NATO-ASI meeting on Mechanical Properties and Behaviour of Materials Having Ultrafine Microstructures, June 29-July 10, Vimeiro, Portugal, 1992.

Paper 3/03241H; Received 7th June, 1993 